\title{
Aerosol physicochemical properties and implications for visibility during an intense haze episode during winter in Beijing
}

\author{
Y. H. Wang et al. \\ Correspondence to: Y. S. Wang (wys@mail.iap.ac.cn)
}




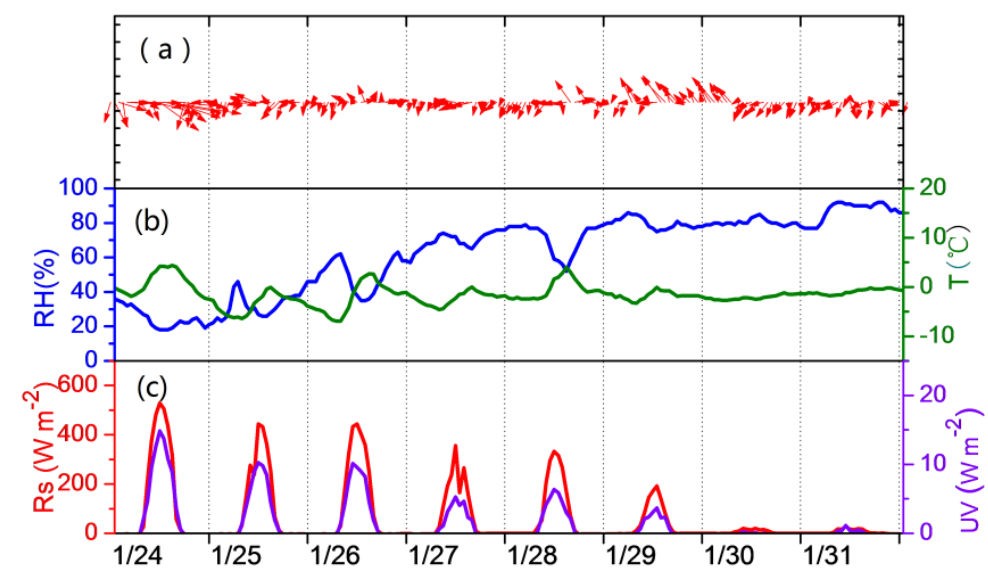

Figure S1 showed the hourly averaged variations of wind direction, wind speed,

relative humidity, air temperature, total radiation and UV radiation during the periods. 


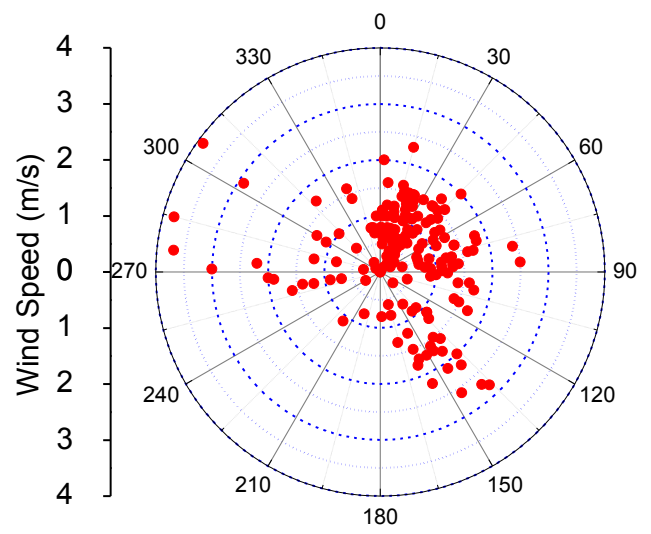

Figure S2 The wind rose of the local wind during observation period. 


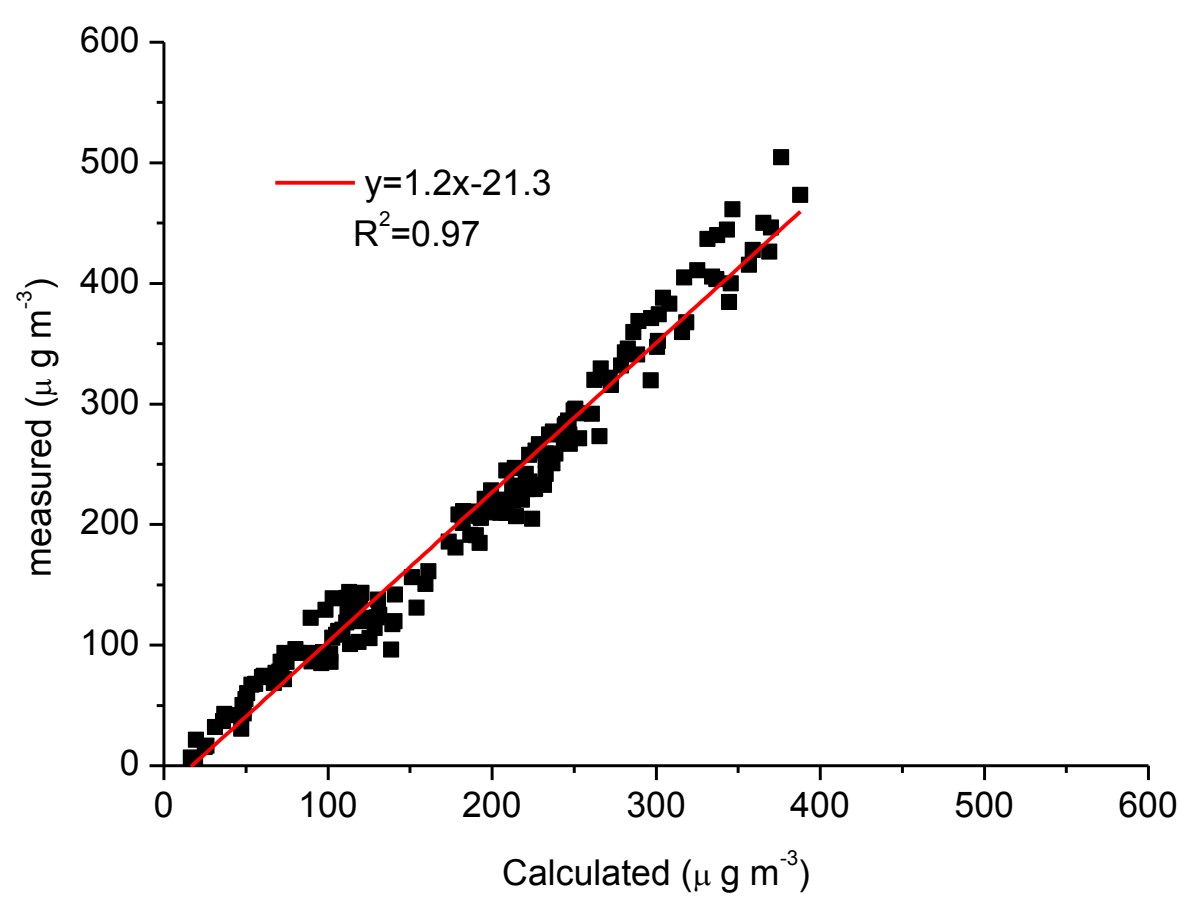

Figure S3 Correlation ship between measured and calculated mass concentration of $\mathrm{PM}_{2.5}$ 


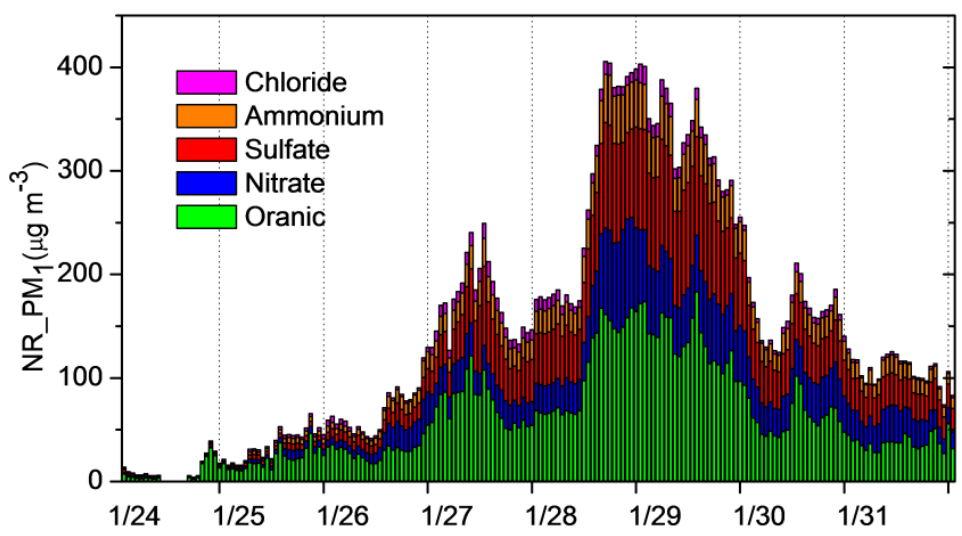

Figure S4 Mass concentrations of organic, nitrate, sulfate, ammonium and chloride during the haze episode 


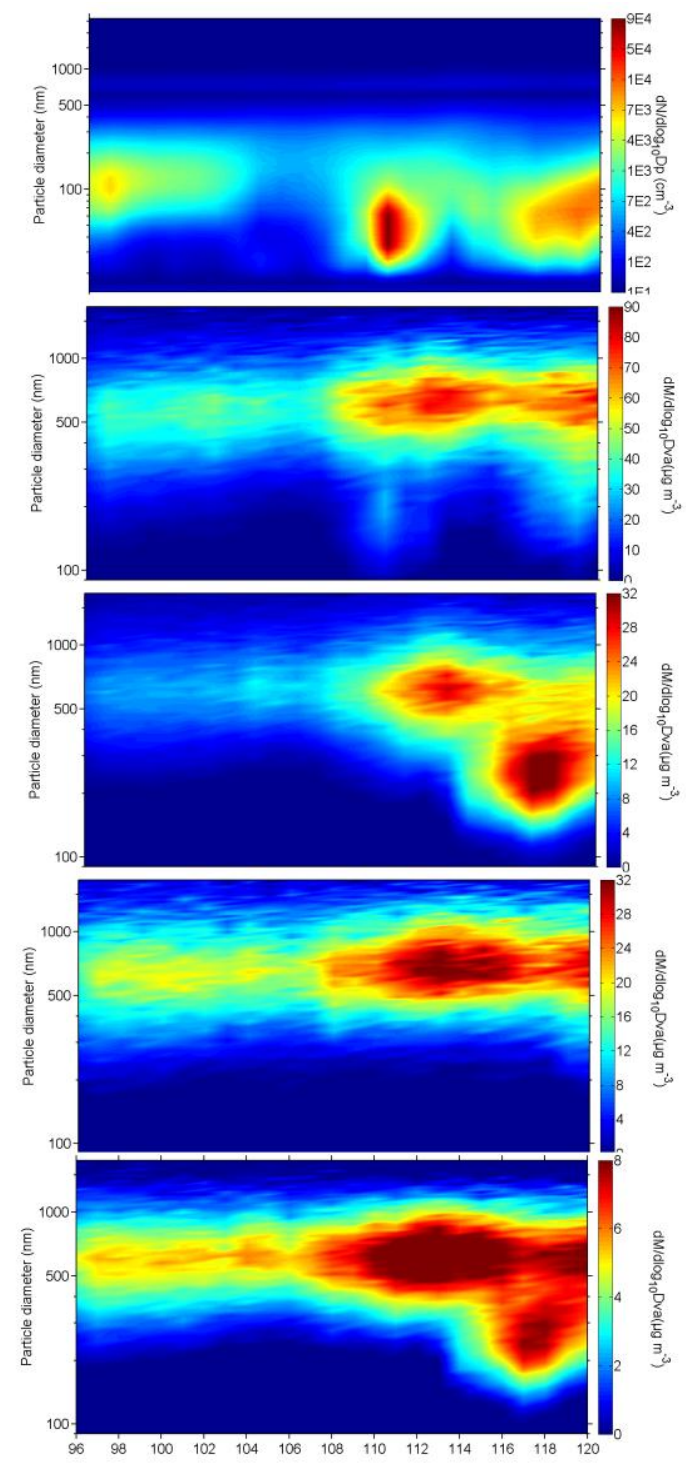

Figure S5 from top to down showed hourly averaged data of Particle number size distribution; size resolved chemical composition of organic; nitrate; sulfate and ammonium during. 


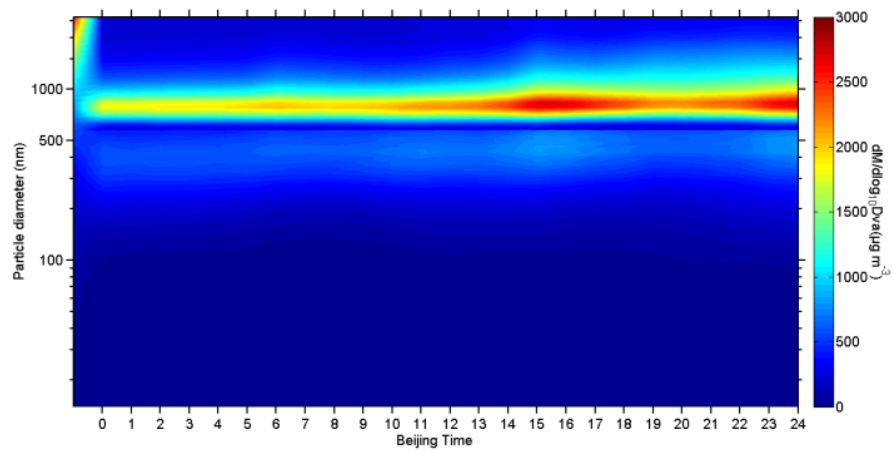

Figure S6 Particle mass size distribution during January 28 


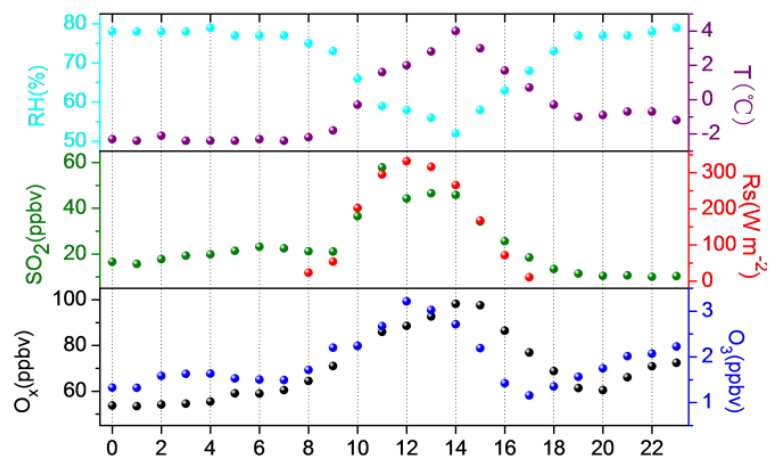

Figure S7 From top to down showed the hourly averaged relative humidity, air temperature, mixing ratio of sulfate dioxide, broadband solar radiation, mixing ratios of $\mathrm{O}_{\mathrm{x}}$ and $\mathrm{O}_{3}$ during January 28 . 


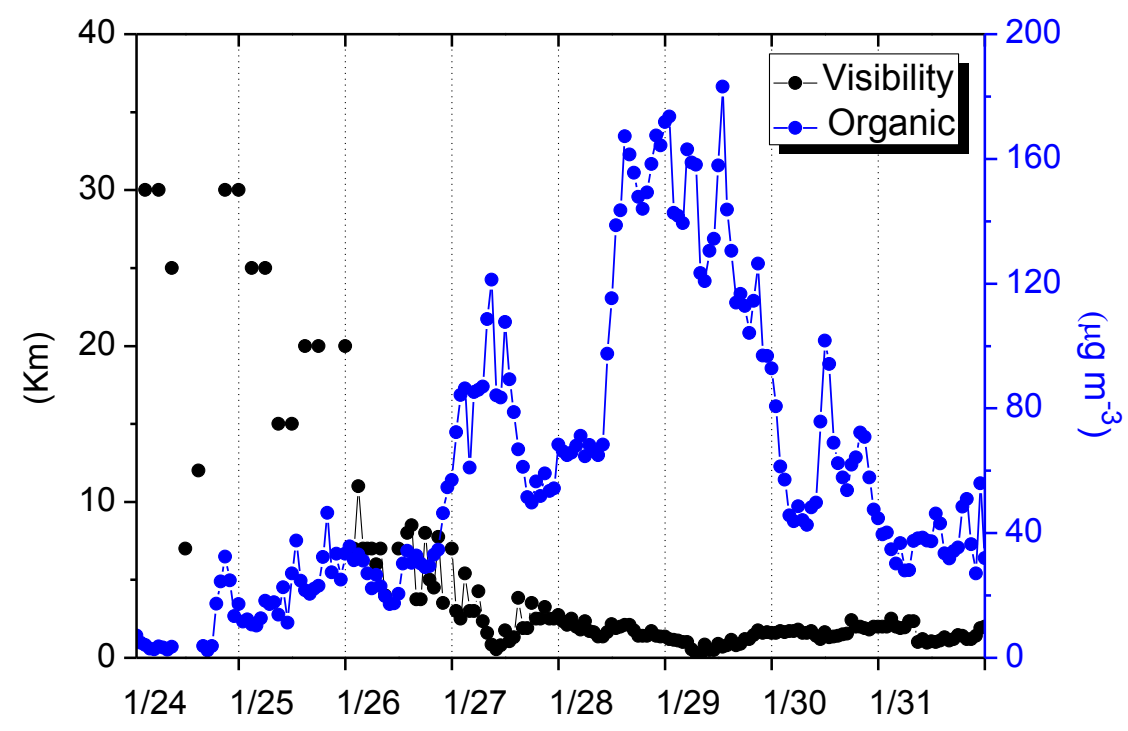

Figure S8 Time series of mass concentration of organic aerosol and visibility during the haze episode 